DOI: http://dx.doi.org/10.22483/2177-5796.2017v19n3p689-710

\title{
Ações docentes no ensino de Filosofia no Ensino Médio
}

\author{
Cleder Mariano Belieri \\ Marta Sueli de Faria Sforni
}

Resumo: Este artigo apresenta resultados de uma pesquisa realizada com a finalidade de investigar como o ensino de Filosofia pode contribuir para o desenvolvimento do pensamento teórico de alunos do Ensino Médio. Com base em aportes da Teoria Histórico-Cultural, foi elaborado um experimento didático, desenvolvido em uma turma de $3^{\circ}$ ano do Ensino Médio de um colégio estadual paranaense. O experimento didático revelou que a narrativa como situação-problema, aulas dialogadas, discussão em grupo e leitura de textos clássicos de Filosofia são ações que favorecem a formação e o desenvolvimento nos estudantes de um pensamento mediado por conceitos filosóficos.

Palavras-chave: Ensino. Aprendizagem conceitual. Filosofia. Teoria histórico-cultural.

\section{Teachers actions in Philosophy teaching in High School}

Abstract: This article presents the results of a research study aimed to investigate ways the philosophy of teaching can be organized so that the theoretical thinking could be developed among high school students. Based on the contributions of Historical-Cultural Theory, it designed a teaching experiment developed with thirdyear high school students in a public school in the state of Paraná, Brazil. The teaching experiment showed that the narrative as a problem situation, dialogued classes, group discussions and reading classical texts of philosophy of history are actions that contribute to the formation and development of thought mediated by philosophical concepts.

Keywords: Teaching. Conceptual learning. Philosophy. Historical-Cultural theory.

Quaestio, Sorocaba, SP, v. 19, n. 3, p. 689-710, dez. 2017. 


\section{Introdução}

A presença da disciplina de Filosofia no Ensino Médio suscitou e tem suscitado diferentes reflexões acerca de seus objetivos, conteúdos e metodologias nesse nível de ensino. Alguns consideram que as aulas de filosofia devam se constituir em momentos de discussão de problema do cotidiano, o que, supostamente, propiciaria o desenvolvimento do pensamento crítico dos estudantes. Esse desenvolvimento seria verificado pela capacidade argumentativa de os alunos posicionarem-se diante de diversos problemas da realidade. Outros consideram que nessa disciplina deva ser priorizado o acesso aos conceitos produzidos pelos filósofos que compõem o acervo histórico desse campo, considerando que o contato com esse conhecimento é a razão da inclusão da Filosofia, como componente curricular, nessa etapa da Educação Básica.

As reflexões tendem a ser polarizadas, levando a um tipo de raciocínio pautado na lógica binária em que se aceita uma ou outra proposição, estabelecendo um estado de tensão entre um ensino voltado para o desenvolvimento do pensamento do aluno ou para aprendizagem de conceitos sistematizados no campo da Filosofia. Um exemplo dessa polarização é a clássica discussão presente na História da Filosofia: aprende-se a filosofar ou se aprende a Filosofia?

Posicionando-se em defesa do desenvolvimento do filosofar, Kant considera que o ensino de Filosofia deve estar voltado para o desenvolvimento da habilidade cognitiva do filosofar que se desenvolve de modo independente da aprendizagem de conceitos filosóficos (KANT, 2003). Assumindo uma perspectiva diferente de Kant, Hegel defende que é possível filosofar desde que os sistemas filosóficos produzidos pelos filósofos no decorrer da história da Filosofia sejam apropriados pelos indivíduos (HEGEL, 1989).

Observa-se que nessas posições antagônicas estão em jogo a natureza do pensamento, sua constituição e suas forças propulsoras, temáticas nas quais Filosofia e Psicologia se entrecruzam. Portanto, o diálogo com a Psicologia pode contribuir para o enriquecimento do debate acerca da relação entre conceitos filosóficos e desenvolvimento do pensamento. Com essa expectativa, nos aproximamos da Teoria Histórico-Cultural ${ }^{1}$.

\footnotetext{
${ }^{1}$ A Teoria Histórico-Cultural tem sua base na chamada "Escola de Vigotski. Vigotski iniciou suas pesquisas [...] em parceria desse grupo [...] em 1924 e se estenderam até 1934, vindo a formar a base teórica da psicologia históricocultural em relação a temas como origem e desenvolvimento do psiquismo, processos intelectuais, emoções, consciência, atividade, linguagem, desenvolvimento humano, aprendizagem" (LIBÂNEO; FREITAS, 2006, p. 1).
}

Quaestio, Sorocaba, SP, v. 19, n. 3, p. 689-710, dez. 2017. 
Segundo essa teoria há estreita relação entre o conteúdo escolar e o desenvolvimento do pensamento, e a função da escola é a de promover o pensamento teórico dos alunos. O desenvolvimento desse tipo de pensamento não ocorre por exercício espontâneo da capacidade reflexiva dos estudantes e tampouco é alcançado por um ensino que objetiva a transmissão mecânica desses conteúdos, mas ocorre mediante a internalização dos instrumentos culturais produzidos pela humanidade (LEONTIEV, 2004). Dentre esses instrumentos, estão os conhecimentos científicos/teóricos. Esses, por sua vez, encontram-se objetivados na linguagem e, segundo Vigotski (2000), num processo de aprendizagem adequadamente organizado, possibilita o desenvolvimento do pensamento dos estudantes.

Aproximando-se da perspectiva de formação defendida pela Teoria Histórico-Cultural, a pesquisa de Lima (2005) sobre o ensino de Filosofia revela a preocupação com um ensino de Filosofia que tenha como finalidade a participação política do aluno na sociedade. Segundo Lima (2005), não basta transformar as aulas em assembleias nas quais os alunos emitem livremente suas opiniões sobre diversos temas, é necessário instrumentalizar o pensamento dos alunos com o conhecimento presente nos textos clássicos de Filosofia. Isso reforça a ideia de se pensar em um ensino de Filosofia no qual os conteúdos ocupem a centralidade desse processo.

Em consonância com Lima (2005), Rodrigo (2007) adverte que as ações didáticas do professor de Filosofia não podem estar dissociadas do conteúdo filosófico, pois é o conteúdo filosófico que permite ao aluno pensar por si. Mas que ações docentes podem favorecer a organização do ensino de Filosofia, a fim de promover a aprendizagem de conceitos filosóficos e, assim, o desenvolvimento do pensamento teórico dos alunos do Ensino Médio?

Esse questionamento nos motivou a compreender como o pensamento teórico se desenvolve e verificar se no caminho de desenvolvimento do pensamento teórico não estariam presentes princípios psicodidáticos capazes de subsidiar o ensino de Filosofia em direção a essa perspectiva de formação.

Ressaltamos que neste trabalho, em alguns momentos, usamos o termo conceito teórico para nos referimos ao conteúdo filosófico. Davidov ${ }^{2}(1988,1982)$ denomina como conhecimento teórico, todas as formas elevadas de consciência social, como as ciências, as artes e a moral.

\footnotetext{
${ }^{2}$ Davidov (1930-1988) incorporou conceitos de Vygotsky, Leontiev e Elkonin para formular uma teoria do ensino: a teoria do ensino desenvolvimental. Para ele, a tarefa da escola contemporânea consiste em ensinar os alunos a orientarem-se independentemente na informação científica e em qualquer outra, ensiná-los a pensar, mediante um ensino que impulsione o desenvolvimento mental (LIBÂNEO; FREITAS, 2006, p. 5).

Quaestio, Sorocaba, SP, v. 19, n. 3, p. 689-710, dez. 2017.
} 
Nesse sentido, entendemos que o conhecimento filosófico pode ser incluido no que Davidov denomina conhecimento teórico. Portanto, ao falarmos de conceitos teóricos, estamos também nos reportando aos conceitos filosóficos.

\section{Quando o ensino é promotor de desenvolvimento do pensamento teórico?}

Para se pensar o ensino de conceitos com vistas ao desenvolvimento do pensamento dos estudantes é necessário compreender que ações e operações mentais estão presentes nos conceitos e que conferem a eles esse potencial formativo.

Leontiev (1969) registra que os conceitos resultam da generalização da experiência humana. Em consonância com Leontiev, Luria (1994) afirma que é por meio de duas funções da palavra que ocorre a elaboração dos conceitos: a de possibilitar ao indivíduo operar com os objetos ausentes, pela sua função representativa e a de relacioná-los a certas "categorias coexistentes que esse objeto possui objetivamente" (p. 20). Ou seja, pela palavra e por meio dela o sujeito abstrai os traços característicos dos diferentes objetos e os generaliza, resultando o conceito.

O processo de elaboração de um conceito ocorre quando o indivíduo abstrai os traços essenciais dos objetos e fenômenos, que podem ou não ser perceptíveis sensorialmente, generalizando-os em determinados grupos pelas relações e associações gerais a que se pode submetê-los, possibilitando-lhe operar com os objetos e os fenômenos mesmo que esses não se façam presentes. Nessa mesma perspectiva, Rubinstein afirma que a generalização significa o “[...] resultado da análise por meio do qual se delimita o essencial” (RUBINSTEIN, 1959, p. 207). Isso nos leva a concluir que quando o sujeito generaliza, coloca em atividade o "[...] processo de formação dos conceitos" (GORSKI, 1959, p. 125). E, quando o sujeito forma para si um determinado conceito por meio da linguagem, ele passa a dominar "[...] automaticamente um complexo sistema de associações e relações em que um dado objeto se encontra e que se formaram na história multissecular da humanidade" (LURIA, 1994, p. 20).

Davidov (1988), ao investigar a formação dos conceitos teóricos, considera que eles são resultados de atividades e procedimentos investigativos em diferentes áreas do conhecimento. Nesses processos investigativos, o cientista ou, em nosso caso, o filósofo, procura superar as generalizações particulares dos diferentes fenômenos que compõe a realidade, buscando localizar 
o princípio geral que abrange diferentes manifestações empíricas. Esse princípio geral, depois de localizado, funciona como unidade explicativa para as referidas manifestações. Por essa razão, Davidov (1988) diz que ao se apropriar de um conceito teórico o sujeito "[...] assume uma particular relação com o objeto, que permite refletir nele o que não é acessível aos conceitos cotidianos" (p. 146).

Para Davidov, ir além das aparências imediatas significa localizar a essência das coisas, localizando uma espécie de núcleo conceitual que determina universalmente os objetos, então quando um conceito teórico é formado, todos os objetos existentes são reduzidos a uma espécie de forma universal. Por exemplo, para os tipos particulares de trabalho há um trabalho humano universal que é a essência das diferentes formas de trabalho (DAVIDOV, 1988).

Considerando a exposição feita até aqui, pode-se concluir que a elaboração de um conceito teórico pelo sujeito ocorre quando ele é capaz de ultrapassar os limites da simples percepção sensorial, conseguindo alcançar a essência dos fenômenos. Para Davidov (1988), no movimento de superação dos conceitos empíricos, formados pela simples percepção sensorial, atingindo a essência que une diferentes fenômenos da realidade desenvolve-se o pensamento teórico. Esse caminho vai "[...] da dedução do singular a partir do universal, como procedimento de ascensão do abstrato ao concreto" (DAVIDOV, 1988, p. 152), ou seja, parte das generalizações das propriedades externas de cada fenômeno (singular) a fim de chegar ao princípio universal (universal) que une os diferentes fenômenos.

Para Davidov (1988, 1982), o conceito teórico, possui o caráter de universalidade e desenvolve-se mediante as capacidades humanas de reflexão e análise. Ao mencionar a importância da reflexão no processo de formação dos conceitos teóricos, Davidov diz que é graças a essa capacidade "[...] que o homem examina permanentemente os fundamentos de suas próprias ações mentais e com eles medeia uma com outras, desentranhando assim suas interrelações internas" (DAVIDOV, 1988, p. 88). Já, a análise permite, durante o processo de formação dos conceitos teóricos, encontrar a

[...] propriedade formalmente geral de certo conjunto de objetos, o conhecimento desta propriedade permite relacionar objetos isolados a uma classe determinada, independentemente de eles estarem ou não vinculados entre si. O processo de análise permite descobrir a relação geneticamente inicial do sistema integral como sua base universal ou essência (DAVIDOV, 1988, p. 89). 
Assim, conforme o exposto, podemos afirmar que, enquanto a reflexão permite ao indivíduo buscar os fundamentos dos seus juízos sobre a realidade, a análise permite generalizar um princípio geral, uma espécie de síntese geral que confere unidade às diferentes representações da realidade. Em concordância com Davidov, Semenova (1996) considera que quando os conceitos teóricos são apreendidos pelo sujeito, esses passam a ser para ele um modo de ação geral, capaz de combinar pelas capacidades de reflexão e análise, as diferentes representações da realidade.

Com os argumentos apresentados por Leontiev (2004) e Davidov (1982, 1988), fica mais clara a relação entre aprendizagem conceitual e desenvolvimento do pensamento, já que, conforme exposto por esses autores, na apropriação de um conceito teórico, o sujeito apropria-se de uma espécie de núcleo que representa a relação geral entre as diferentes representações gerais da realidade e da atividade de pensamento objetivada nesse conceito.

Nesse sentido, um ensino de Filosofia que tem como foco o desenvolvimento do pensamento teórico do aluno deve promover a apropriação de princípios gerais, capazes de unificar representações particulares de diversos fenômenos. Esse princípio, uma vez internalizado pelo estudante, passa a mediar sua relação com o mundo, possibilitando a modificação do seu pensamento sobre questões históricas, sociais, estéticas, epistemológicas, científicas, éticas e políticas, visto que, além dos conhecimentos adquiridos mediante a sua própria experiência, ele passa a contar, também, com um repertório cultural muito mais amplo para lidar com os fenômenos.

Reconhecemos que a Filosofia é um produto não material, mas o conhecimento produzido nessa área materializa-se na linguagem, em conceitos filosóficos, organizados em sistemas de conceitos. Esses conceitos estão presentes nos textos dos clássicos de Filosofia. Desse modo, quando nos apropriamos, por exemplo, do conceito de ideia platônica, nos apropriamos da atividade mental realizada na elaboração desse conceito e este passa a mediar a nossa relação com o pensamento filosófico e com o mundo material.

A nossa percepção acerca dos fenômenos, nossa atenção para determinados aspectos, nossa imaginação e raciocínio são modificados à medida que nos apropriamos de outro modo de refletir a realidade objetiva presente nos conceitos filosóficos. Isto é, nossa interação com o mundo passa a ser mediada por outros instrumentos simbólicos, de caráter mais complexo, o que a torna cada vez menos empírica e intuitiva e cada vez mais teórica. Desse modo, os conceitos 
filosóficos passam a ser utilizados para compreender diferentes fenômenos. O pensamento teórico, na condição de um pensamento lógico-verbal em sua forma mais complexa, oferece condições para o aluno "ultrapassar os limites da percepção sensorial imediata do mundo exterior, refletir conexões e relações complexas, formar conceitos, fazer conclusões e resolver complexas tarefas teóricas" (LURIA, 1994, p. 17).

A aprendizagem de conceitos teóricos, em nosso caso, os conceitos filosóficos, promove o desenvolvimento das capacidades psicológicas superiores do aluno, como atenção, percepção, memória, raciocínio, imaginação, reflexão e análise. Entretanto, a prática escolar bem como pesquisas sobre o ensino (BELIERI; SFORNI, 2012) nos revelam que nem toda forma de ensino de conceitos tem esse potencial formativo. Como, então, organizar o ensino para que promova esse desenvolvimento?

\section{A pesquisa de campo: o experimento didático como procedimento metodológico}

Ancorados em pressupostos da Teoria Histórico-Cultural, buscamos organizar um experimento didático com o objetivo de analisar modos de organização do ensino que favorecem ou dificultam aprendizagem de conceitos filosóficos como meio de desenvolvimento do pensamento teórico dos alunos do ensino médio. No experimento didático (FREITAS, 2010; AQUINO, 2013), o pesquisador atua como professor ou em conjunto com o professor, em nosso caso, somos professor da turma em que desenvolvemos o experimento. São realizadas intervenções em contexto real de sala de aula, com a intenção de analisar o impacto de determinados procedimentos didáticos na aprendizagem de conceitos por parte dos alunos, ou seja, atividades de ensino são organizadas e desenvolvidas para fins de pesquisa.

O experimento, portanto, se constitui num procedimento que possibilita ao pesquisador coletar os dados da realidade em seu movimento. Nesse tipo de pesquisa, o que se pretende é captar as situações sociais de desenvolvimento que, na escola, se expressam nãos modos de ensino de um determinado conteúdo.

Durante o experimento, interviemos e acompanhamos o trajeto dos alunos rumo ao desenvolvimento do pensamento teórico por meio da aprendizagem de conceitos teóricos. Por isso, nossas categorias gerais de análise foram as capacidades humanas necessárias para a elaboração dos conceitos teóricos como a reflexão, a análise e a síntese (DAVIDOV, 1982, 
1988). As ações e operações propostas aos alunos por meio do experimento tentaram subsidiar o desenvolvimento dessas capacidades para que os alunos pudessem internalizar uma síntese geral e passassem a utilizá-la como instrumento mediador entre eles e a realidade (LEONTIEV, 2004).

Nosso experimento foi desenvolvido com alunos do $3^{\circ}$ ano do Ensino Médio de um colégio estadual do Estado do Paraná. A turma era composta por 25 estudantes, cuja idade oscilava entre 16 e 18 anos. Nesse grupo, 80\% dos alunos eram trabalhadores, desempenhando funções como: empregada doméstica, balconista, carpinteiro, lavrador (a), vendedor (a) ambulante, atendente de loja e recepcionista. Noventa por cento dos pais desses alunos possuem Ensino Fundamental incompleto, 9\% cursaram o Ensino Médio e apenas 1\% concluiu o Ensino Superior. Os pais atuam no mercado de trabalho como metalúrgicos, agricultores, empregadas domésticas, carpinteiros, costureiras, do lar, mestre de obras, vendedores autônomos, um funcionário público estadual e uma professora dos anos iniciais do Ensino Fundamental.

Os dados foram coletados por meio de registros orais e escritos, durante a realização do experimento. As intervenções foram realizadas obedecendo ao turno e ao horário em que os alunos normalmente frequentavam a escola e as aulas de Filosofia.

\section{Definição do conteúdo de ensino e de algumas ações docentes}

O conteúdo trabalhado foi o conceito de alienação, por ser um conteúdo previsto para o semestre no qual realizamos o experimento. Motivados pelo pensamento de Hegel sobre o ensino de Filosofia de que “[...] Graças à aprendizagem [...] uma vez cheia a cabeça de pensamentos, terá então também a possibilidade de ela própria fazer avançar a ciência e de lhe conquistar uma verdadeira originalidade" (HEGEL, 1989, p. 373), pretendíamos que os alunos internalizassem o núcleo conceitual, ou seja, o princípio geral básico que dá unidade ao sistema conceitual que constitui o conceito de alienação.

Nossos estudos haviam revelado que o princípio geral que une as diferentes representações sobre alienação estaria relacionado a perder o ser; perder que o faz ser; perder a humanidade; perder o que o faz ser o que é; perder a essência que define o homem como tal. Desse modo, a alienação seria, de um modo geral, a perda do ser. Assim, o homem estaria alienado quando perdesse o que o define como homem. Como a concepção de homem varia em cada linha filosófica, o conceito de alienação acompanha essas variações. Assim, a identificação 
do nexo conceitual entre a essência humana e a negação dessa essência seria uma chave de leitura para a compreensão do conceito de alienação em várias teorias, estando ela explicitamente presente ou não em cada uma delas. Ou seja, essa seria a generalização que permitiria o movimento em direção a várias teorias e fenômenos particulares. Devido às poucas horas possíveis para a realização do experimento, optamos por focar o ensino no estudo da produção de apenas um autor. Foi trabalhado, então, o conceito de alienação no pensamento de Sartre.

A análise de princípios acerca do processo de aprendizagem presentes na Teoria Histórico-Cultural e em publicações sobre o ensino de Filosofia, como Rodrigo (2007) e Gallo (2012), nos permitiu levantar duas ações didáticas potencialmente capazes de contribuir com o ensino de Filosofia: uso da narrativa como situação problema e organização de momentos de diálogo entre o professor-aluno e aluno com seus pares.

Recorremos ao uso da narrativa como situação problema por considerarmos que a aprendizagem requer participação ativa do estudante, ou seja, para que ele possa apropriar-se de um conceito teórico, deve reproduzir internamente a atividade humana que se encontra objetivada nesse conceito (LEONTIEV, 2004). Entendemos que para provocar essa reprodução interna, ou seja, a atividade psíquica dos estudantes em sintonia com a atividade mental objetivada no conceito, deveríamos inseri-los em situações em que há um problema que possa ser resolvido pela mediação do conceito.

Gallo (2012), ao escrever uma didática para o ensino de Filosofia no Ensino Médio, compreende o uso de situações problema um momento de aproximação do aluno de conceitos filosóficos. Para Rodrigo (2007), o uso de situações problema no Ensino de Filosofia leva o aluno a buscar a compreensão dos nexos existentes entre os problemas cotidianos e os filosóficos, despertando nele um apetite epistemológico. Moura e Moura (1998), pautados em princípios da Teoria Histórico-Cultural, fazem a defesa do uso de narrativas no ensino, denominando-as história virtual do conceito. Para os autores, elas permitem inserir o indivíduo em uma situaçãoproblema na qual os personagens que a compõem poderiam ter vivido situação semelhante em algum momento da história da humanidade, reproduzindo a atividade humana que deu origem aos conceitos que serão ensinados.

Em nossa pesquisa, a situação problema foi apresentada por meio de uma narrativa que relata as angústias e dilemas de uma adolescente judia privada de liberdade. A narrativa foi elaborada com base em um capítulo do livro O Salto para a vida, de autoria de Célia Valente 
(1999), trata-se de uma história verídica que retrata a perseguição dos nazistas aos poloneses durante a segunda guerra mundial.

A narrativa elaborada requeria dos alunos posicionamentos acerca de conflitos apresentados pela personagem. Nosso objetivo era o de criar o motivo de aprendizagem nos estudantes, já que o problema assumia a função de desencadear uma atividade reflexiva em torno de uma situação em que o conceito de alienação se fazia presente, porém não de modo explicito. Além da necessidade de criar um motivo para a aprendizagem, a narrativa nos pareceu importante também pela razão exposta por Moura e Moura (1998): permitir a reconstituição histórica de alguns conceitos. Assim, na elaboração da narrativa, o conflito tinha a intenção de recuperar os traços essenciais do conceito de alienação. Nossa finalidade era a de inserir os alunos em um contexto histórico que possivelmente tenha gerado a necessidade de Sartre teorizar a respeito da condição humana de alienação. Ao procurar reproduzir a base material e a historicidade do pensamento do autor, poderíamos reconstituir, como afirma Hegel (1989), o caminho que os filósofos realizaram para elaborar os seus conceitos.

Durante a pesquisa, optamos por mediar os processos de reflexão, análise e generalização substancial de forma coletiva. Entendíamos que esse procedimento poderia favorecer a aprendizagem por meio de um processo de interiorização da atividade coletiva para a atividade individual (DAVIDOV, 1988) ou, como afirma, Vigotski (2000), do plano interpessoal para o plano psíquico. Assim, durante a atividade de ensino, organizamos momentos coletivos de apresentação das respostas dadas ao problema pelos grupos; seguida da elaboração de uma resposta coletiva da turma e, posteriormente, respostas individuais.

\section{O conceito filosófico em uma atividade de ensino}

\section{a) Reflexão: a narrativa na atividade de ensino}

Inicialmente, solicitamos aos alunos que formassem pequenos grupos e procedessem à leitura da narrativa. Como dissemos anteriormente, selecionamos, para isso, uma narrativa que tinha como personagem principal Léa, uma jovem judia que vivia na Polônia e que foi privada de sua liberdade durante a ocupação da sua cidade pelos nazistas. O contexto vivido pela personagem leva à reflexão acerca da relação entre a humanidade e a condição de realização dessa humanidade. Acreditávamos que o problema presente na narrativa desencadeasse a Quaestio, Sorocaba, SP, v. 19, n. 3, p. 689-710, dez. 2017. 
necessidade de reflexão sobre o tema e, portanto, gerasse o motivo de aprendizagem conceitual nos estudantes. Após a leitura e discussão, os alunos deveriam apresentar uma resposta que representasse a síntese do grupo acerca do problema por nós elaborado, disposto ao final da narrativa:

Mas a que fim estava voltada a minha opção em continuar varrendo, a um fim meu, próprio, interno (a minha vontade), ou a um fim determinado exteriormente? Estaria de fato deixando de ser humana caso continuasse a varrer todos os dias aquelas ruas? Não estaria submetida a essa condição por ter como maior valor a possibilidade de poder viver? A que fim e o que justificava o modo de agir dos goim, dos jundenrat e do prefeito? A atitude dos goim, dos jundenrat e do prefeito também consiste em abrir mão da sua humanidade? Estariam os goim, os jundenrat e o prefeito em uma condição semelhante a minha? Por quê? Que condição traduz a minha atitude de continuar varrendo? Estaríamos em uma condição de alienação? (Professor).

Acreditamos que a chave para a resolução do problema apresentado seria o uso do conceito de alienação. Mas não considerávamos que a definição verbal desse conceito já no início da atividade possibilitaria aos estudantes a compreensão dele. Entendíamos que, no processo de elaboração da síntese, capacidades mentais são colocadas em movimento e, por isso, desenvolvidas. Assim, mesmo que por um caminho mais longo do que o trilhado pelo ensino assentado na definição e repetição dos conceitos pelos alunos, esse poderia ter maior impacto sobre o desenvolvimento do pensamento dos estudantes. Na tentativa de responderem o problema presente na narrativa os alunos Kal, Lídia e Maya apresentaram para o grupo os seguintes argumentos:

Ela fez o que ela queria, ela fez a vontade dela, foi uma opção dela (Kal).

Por que naquela época mesmo que os nazistas vissem a pessoa varrendo ou não fazendo nada eles matavam. Eles achavam que tinham que matar e já matavam. Eles matavam também para mostrar o poder... (Adri).

Então ela preferia a vida e não ligava em perder a liberdade dela, mas preferia continuar vivendo (Lídi).

Nos diálogos, verificamos que as perguntas apresentadas possibilitaram o envolvimento desse grupo de alunos com a temática desencadeadora da reflexão. É possível observar que Kal utilizou os conceitos de forma espontânea, sem apresentar um núcleo comum (DAVIDOV, 1982, 1988) existente entre eles. A ausência do conhecimento filosófico faz com que a compreensão inicial do texto tenha sido mediada por significações espontâneas e de senso comum. Podemos observar isso na fala da aluna Kal quando postula que "Léa fez o que ela queria, ela fez a vontade dela, foi uma opção dela”. As significações apresentadas pela aluna são provenientes do cotidiano, possivelmente de vivencias em espaços não escolares.

Quaestio, Sorocaba, SP, v. 19, n. 3, p. 689-710, dez. 2017. 
Até aqui percebemos nas afirmações dos alunos que atenção deles não estava dirigida para um sistema conceitual possível para se analisar a narrativa. Fizemos uma nova intervenção com a intenção de levá-los à busca de elementos do texto que poderiam ajudá-los a responder ao problema:

No texto há informações que possam levar vocês a um consenso? Talvez exista! No texto há alguma relação entre a condição de alienação e a perda da liberdade? É possível definir o que é ser humano a partir do texto? Há uma relação entre ser humano e ser livre? (Professor).

Ao orientá-los a buscar no texto evidências que sustentassem o que afirmavam, consideramos ter apresentado aos alunos um modelo de interação com o texto. Isso ocasionou mudanças na resposta do grupo, já que eles perceberam que a resposta não deveria ser extraída apenas da opinião pessoal, mas também da interpretação do texto. Dialogar com o texto exige que o leitor saia de uma visão já consolidada sobre alguns fenômenos e insira o olhar do outro na sua análise. Nessa interação, ele pode modificar, complementar, incorporar, consolidar ou abandonar o pensamento pré-existente, ampliando seu repertório cultural. Contudo, para fazer com que os alunos tivessem como referência também o texto para elaborarem suas respostas e não se mantivessem no universo das opiniões com pouco teor argumentativo, foi necessária nossa constante intervenção:

E se ela perde a liberdade ela perde a sua humanidade, de acordo com o texto? (Professor).

Não, porque ela não tem escolha, ela não tem vontade própria (Daia).

Se ela não tem a possibilidade de escolher entre varrer e não varrer, ela é livre? (Professor).

Não (Grupo).

Então ela perde a sua humanidade por não poder escolher entre varrer e não varrer? O que é essa dignidade? (Professor).

Se ela não seguir as ordens dos alemães ela só estará perdendo a dignidade, ela estará traindo o povo dela... Traindo a tradição dela, os ideais dela... (Daia).

Se ela não cumprir as ordens dos alemães ela trairá o seu povo? (Professor).

Para ela é isso (Daia).

Um dado importante é revelado na fala de Daia quando interrogada sobre a condição de submissão às ordens nazistas, responde: “para ela é isso”. A resposta de Daia apresenta indícios de uma ruptura entre o pensar pela própria experiência e o pensar por meio do pensamento do outro. Esse é um passo importante para o desenvolvimento do pensamento filosófico, pois implica apropriar-se da lógica de um sistema explicativo sobre os fenômenos e por meio dele 
pensar a realidade. Isso não significa, necessariamente, a aceitação desse sistema, mas a sua compreensão, o que pode levar o sujeito a aceitá-lo ou superá-lo de forma consciente.

A interlocução com o texto, mediada pelo professor, foi o desencadeador desse processo. Contudo, até esse momento não havíamos percebido, nas respostas dos alunos, indícios que contemplassem a relação existente entre os conceitos de homem, liberdade e vontade, nem mesmo faziam menção a outras situações particulares que pudessem explicar outras condições existenciais como alienadas ou alienantes. Para que os alunos avançassem nessa direção, conforme os estudos de Vigotski (2000), Vygotski (1993), Davidov (1982, 1988), Leontiev (1969, 2004), Rubtsov (1996), Semenova (1996) e Sforni (2004, 2015) seria necessário que os alunos se apropriassem de uma síntese geral e que por meio dela fosse possível a explicação de diferentes fenômenos, elevando o conceito de alienação do patamar de particularidade para o da universalidade (Davidov, 1988).

\section{b) A análise na atividade de ensino: em busca de um princípio geral}

Uma nova ação foi proposta: os alunos teriam que encontrar um princípio comum entre as várias definições presentes em dicionários, confrontando esse princípio aos elementos do conceito de alienação inferido da análise da narrativa. Realizamos esse procedimento por acreditarmos que a localização de um princípio geral, resultado da análise das diferentes significações do conceito de alienação, pode permitir a modificação do modo de pensar esse conceito, incluindo diferentes situações que podem ser por ele explicadas (VIGOTSKI, 2000; LURIA, 1994).

A finalidade dessa ação era a de que, por meio da análise, os alunos elaborassem uma síntese, mesmo que provisória, sobre a alienação, inserindo em um sistema conceitual os conceitos de homem, liberdade, vontade e essência.

No momento de preparação das aulas, para elaborarmos a síntese sobre o conceito de alienação, recorremos a textos clássicos de autores de Filosofia, como os de Hegel, Marx e Sartre, a dicionários do pensamento filosófico e da língua portuguesa. Tentamos reproduzir esse mesmo percurso com os alunos em sala de aula. Isso demonstra a necessidade de o objeto de ensino ser, antes, objeto de estudo pelo próprio professor. 
A fim de estimular o processo de análise pela via da reflexão para a elaboração de uma síntese geral (DAVIDOV, 1988; RUBTSOV, 1996; SEMENOVA, 1996), foram apresentadas três definições sobre alienação, sendo duas definições de dicionários da língua portuguesa e uma de um dicionário de filosofia. Para orientar o processo de análise dessas definições, na busca por um princípio comum entre elas, lançamos as seguintes questões: E se pensarmos assim: os três conceitos que estão disponíveis para vocês têm algo em comum. O que há em comum entre os três? Se nós fossemos dizer: há em comum entre os três... O que vocês definiriam?

Adri tenta responder às questões dizendo:

Como quando a gente viu primeiro, a gente não achou que ela havia perdido a sua humanidade. Mas vendo aquela parte que ela lembra que o professor disse o ato mais humano é quando a pessoa usa a sua liberdade para escolher... Ela não é mais livre eu tenho que usar a minha liberdade para fazer a escolha do que еи quero...

Podemos perceber que Adri retoma a discussão apresentada na narrativa e parece agora reconhecer que a identificação de algo como desumano depende da concepção de homem que se tem.

Com isso, notamos que a leitura das definições de alienação, presentes nos dicionários, começa a permitir aos alunos o afastamento necessário para pensarem no conceito (universal) e não apenas na situação presente na narrativa (particular). Contudo, percebíamos que os alunos continuavam presos ao que havia sido trabalhado na narrativa, não conseguindo utilizar o conceito de alienação como um modo geral de ação.

Com base nessas constatações, percebemos a necessidade de, além do conceito de liberdade e vontade, os alunos elaborarem o conceito de essência humana. Pois, como dissemos anteriormente, a perda do que define o homem como homem, demonstraria uma condição de alienação. Assim, por meio de uma exposição e com base em um dicionário de Filosofia apresentamos aos alunos o significado de essência. Isto permitiu aos alunos modificarem a sua relação com a narrativa, passando a utilizar o conceito filosófico de alienação como chave de leitura. É o que podemos constatar no diálogo a seguir, realizado após a apresentação do conceito de essência aos alunos:

O homem está alienado quando perde a sua essência! (Lídi).

Como? (Professor).

Quando ele perde a sua essência! O que é natural dele! (Lídi).

Quaestio, Sorocaba, SP, v. 19, n. 3, p. 689-710, dez. 2017. 
Por que aqui diz que alienação é perder aquilo que você tem, aquilo que você é! (Kal).

Todos concordam? (Professor).

Sim (Alunos).

É isso! (Lídi).

Por meio da reflexão e da análise, os conceitos filosóficos começam a ser conscientizados pelos alunos. Com isso, o pensamento dos alunos sofre modificações, pois o conceito passa a ser, para eles, instrumento mental, ou seja, elemento mediador entre seu pensamento e o fenômeno descrito no texto. O pensamento mediado por conceitos é o que permite, como postula Luria (1994), ter acesso a leis inacessíveis à percepção imediata do fenômeno. Mas esse processo estava ainda em seu início. Nossa intenção, naquele momento, era a de que os alunos conseguissem relacionar o conceito de essência aos conceitos de liberdade, homem, razão, vontade e pudessem, mediante isso, pensar de um modo mais geral a alienação, reunindo, como propaga Davidov (1988), as diferentes representações em um núcleo comum. Assim, realizamos outra intervenção:

Existe uma essência humana? Como vocês disseram alienação é perder o que faz ser o que é. Então se alienação é perder o que faz ser o que é, cada um possui uma essência individual, ou a essência é humana, ou seja, geral entre todos os homens, isto é, os seres humanos assemelham-se por portarem a mesma essência? (Professor).

A essência é uma característica humana, mas cada um tem a sua (Adri).

Vou refazer a pergunta: nós nos assemelhamos, ou seja, somos chamados de seres humanos porque possuímos uma essência humana, por que possuímos algo que nos assemelha e o que nos assemelha é essa essência ou cada um de vocês possui uma essência? (Professor).

É a primeira (Kal).

Qual é o conceito que está na narrativa que define o homem? (Professor).

Vontade... (Alunos).

O conceito de essência parece ter sido incluído na concepção dos alunos acerca da alienação. Percebemos que o percurso que realizamos procurou dirigir a atenção dos alunos para o conceito de essência com o objetivo de que esse conceito fosse inserido na relação conceitual que forma o conceito de alienação. Depois de realizarmos a tentativa de elaboração de uma síntese geral sobre o conceito de alienação, passamos à análise de excertos do texto $O$ Existencialismo é um Humanismo (SARTRE, 2009), a fim de identificar, por meio da reflexão e análise, um possível conceito de alienação em Sartre mediante a síntese já elaborada. Procuramos observar se houve mudança na compreensão do conceito de alienação por parte dos alunos 
devido o contato com o pensamento filosófico de Sartre, e se esse contato proporcionou uma interação teórica como o pensamento desse filósofo.

Para o estudo dos fragmentos do texto de Sartre elaboramos algumas questões, cujas respostas contribuiriam para verificarmos se os alunos haviam internalizado a relação essencial entre os conceitos de homem, liberdade, essência e vontade, pois acreditávamos que a resolução das questões exigiria do aluno o uso desses conceitos filosóficos como instrumentos para a análise do texto de Sartre.

Como Sartre analisaria a situação vivida por Lea Bleimam e os demais personagens da história que lemos? Vamos ver como Sartre resolveria esse problema? O que seria alienação em Sartre? Em grupo vamos ler alguns fragmentos do livro de Sartre, $\boldsymbol{O}$ Existencialismo é um Humanismo, para tentarmos resolver os seguintes questionamentos: O que é o homem para Sartre? Podemos dizer que há alienação para Sartre? Quando? Como pode ou não ser percebida a Alienação para Sartre? (Professor).

Após analisar as repostas dos alunos, apresentamos à turma uma síntese das respostas por eles elaboradas com o objetivo de auxiliá-los na localização do conceito de alienação em Sartre. Essa intervenção foi necessária, pois as repostas apresentavam um conceito de liberdade incondicionada o que se contrapõe ao pensamento de Sartre. Eles utilizaram como instrumento mental para a realização da leitura, em termos Vigotskianos, um conceito espontâneo de liberdade. Para a superação dessa compreensão realizamos uma nova intervenção:

Parece que não é bem isso que está no pensamento do Sartre. Conseguem perceber isso? (Professor).

Sim (Parecem concordar com o que dissemos) (Alunos).

Agora sim! (Eric).

Legal! Por que uma vez que eu escolho o outro, escolho a humanidade isso implica dizer que eu tenho que agir sob a responsabilidade da minha ação, contudo ao mesmo tempo eu tenho que ser arbitrário às imposições que são feitas por grupos sociais, pela mídia, por certos governos ditatoriais... Sartre parece querer que eu me oponha a isso. Eu tenho que me opor a essa situação. Eu não posso de forma alguma abrir mão da minha liberdade e da minha ação individual. Pois, se eu abrir mão da minha liberdade, o que acontecerá comigo? (Professor).

Estarei alienado (Adri).

Se não posso escolher devido imposições que me foram feitas... (Professor).

Você está alienado (Eric).

E no caso da Lea Bleimam, que abriu mão da vida que tinha? (Professor).

Ela está alienada... (Adri).

Acreditamos que as respostas dadas pelos alunos Adri "Ela está alienada”, Eric "Você está alienado" e demais alunos "Está alienado", podem tanto revelar a compreensão do conceito de alienação presente no pensamento de Sartre, como a repetição de uma resposta que eles Quaestio, Sorocaba, SP, v. 19, n. 3, p. 689-710, dez. 2017. 
perceberam ser a esperada pelo professor. Faz-se, então, necessário verificar se os alunos de fato se apropriaram do conceito de alienação, para isso apresentamos outra situação particular que poderia ser analisada mediante o conceito de alienação.

\section{c) O conceito filosófico como conteúdo do pensamento}

Solicitamos aos alunos que observassem uma tira em quadrinhos e primeiramente discorressem sobre o que viam. Isso nos possibilitaria observar se os alunos perceberam por meio da síntese geral vista anteriormente (DAVIDOV, 1988) que o material representava um tipo particular de alienação e poderia ser explicada por meio do conceito de alienação. Nesse momento, buscamos estabelecer "[...] um sistema de problemas particulares, que é possível resolver aplicando o modo geral de resolução" (SEMENOVA, 1996, p. 162).

Figura 1 - Tira do cartunista Quino

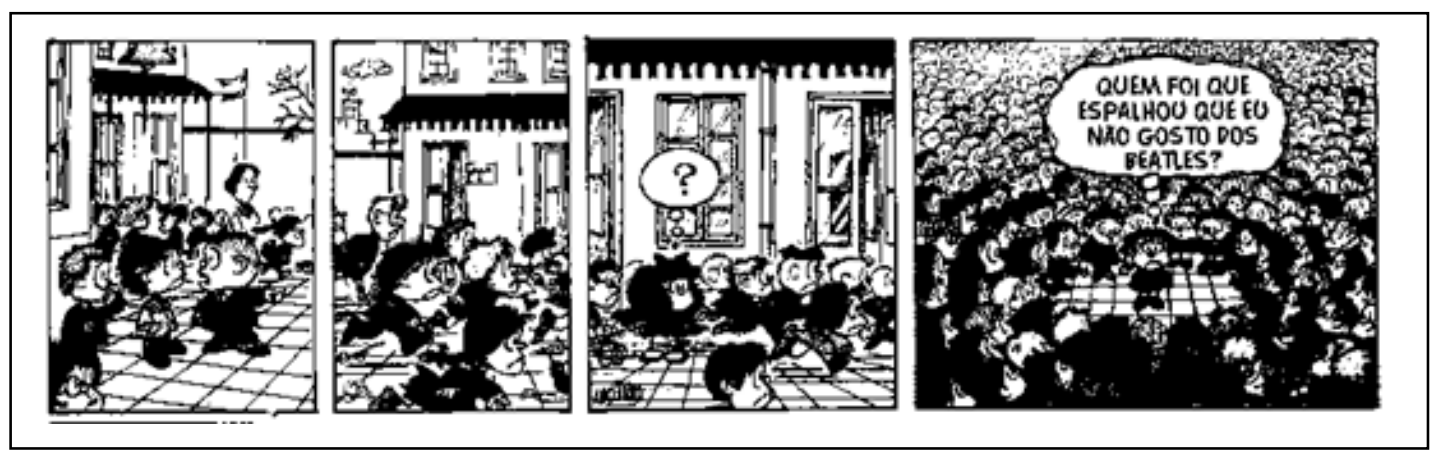

Fonte: TEJÓN, Joaquín Salvador Lavado. Toda Mafalda. São Paulo: Martins Fontes, 2003. p. 145.

Na primeira tentativa de realização da análise da tira, Adri e Eric afirmaram:

O que se pode analisar é que estava uma multidão toda lá correndo, daí ela foi ver! Por que um dentre todos não gostava do Beatles, e daí todo mundo ficou assustado, porque se todo mundo gosta dos Beatles, por que uma única pessoa não vai gostar (Adri).

E nesse caso, gostar dos Beatles é algo bom para a humanidade? (Professor).

De certa forma você gostar das músicas é bom, mas você gostar deles... Bem... Isso não vai te favorecer em nada... Eles não vão dar metade da grana deles pra você!! (risos...) (Adri).

Notamos que Adri não utilizou o conceito de alienação para analisar a tira. A leitura da tira foi realizada por Adri com base no senso comum, com informações possivelmente advindas de espaços não escolares como o convívio social quando ela disse "porque se todo mundo gosta 
dos Beatles, por que uma única pessoa não vai gostar”. Com isso, modificamos a pergunta tentando dirigir a atenção dos alunos para a condição em que a personagem principal da tira encontrava-se.

\footnotetext{
Mas observem esse menino no meio do grupo dizendo: quem foi que disse que eu não gosto dos Beatles? Analisem a condição que ele se encontra! Ou que condição as outras pessoas se encontram? (Professor).

As outras pessoas estão alienadas! (Kal).

Por quê? (Professor).

Porque eles estão tipo assim alienados daquilo, você entende? Todo mundo gostando... (Adri).

É no caso todo mundo quer aquilo, mas ele no caso... ele usou liberdade dele para achar que aquilo era ruim! Eles se colocaram em condição de alienação, por que ninguém pensou: "Por que eu gosto dos Beatles?" (Kal).

Os demais concordam com o que os colegas disseram? (Professor).

Sim! (Alunos).

Mas isso não é negar a liberdade da pessoa, a condição humana que o Sartre disse? (Professor).

Isso é estar alienado! (Daia).

E não é porque todo mundo gosta que ele tem que gostar também. Ele tem que gostar de acordo com a sua vontade! Vai deixar de ser o que ele é! (Pat).
}

A análise da tira nos permitiu acompanhar e avaliar se os alunos internalizaram uma síntese geral de alienação e conseguiam dar movimento a essa síntese tomando-a como base para analisar outras situações.

Constatamos que a aluna Kal, ao dizer “[...] mas ele, no caso, ele usou liberdade dele para achar que aquilo era ruim!”, apresentou indícios do conceito de alienação apoiada nos pressupostos presentes no pensamento de Sartre. Ao dizer "[...] no caso, todo mundo quer aquilo, mas ele no caso... ele usou liberdade dele para achar que aquilo era ruim! Eles se colocaram em condição de alienação, por que ninguém pensou por que eu gosto dos Beatles?",, a aluna Kal apresenta um modo de ação da Filosofia que é o pensamento reflexivo. A mesma afirmação realizada por Kal também revela a presença do conceito de alienação como conteúdo de pensamento, pois ela não se prende a uma representação particular, mas a analisa por meio de uma síntese geral.

A aluna Pat conseguiu expressar a relação entre liberdade e vontade, conceitos essenciais para compreender o conceito de alienação em Sartre. Percebemos isso quando, na tentativa de analisar a tira, ela diz: "E não é porque todo mundo gosta que ele tem que gostar também. Ele tem que gostar de acordo com a sua vontade! Vai deixar de ser o que ele é!”. Isso pode 
demonstrar que a aluna Pat faz uso de uma síntese de alienação, mas manteve sua resposta nos limites do pensamento de Sartre. Isso lhe proporcionou outro nível de interação com o fenômeno apresentado na tira. Porém, ela não apresentou uma generalização mais geral acerca do conceito de alienação como a aluna Kal.

Observamos que nem todos os alunos da turma chegaram a níveis de pensamento como evidenciados por Pat e Kal. Os alunos não são autômatos que caminham em marcha no mesmo ritmo e direção, há diferentes pontos de partida entre eles, diferentes tempos, ritmos e formas de manifestação da aprendizagem em uma turma. O importante é que ninguém permaneça no seu próprio ponto de partida e que o professor tenha como objetivo que sua ação afete a todos. Cabe destacar também que alguns resultados positivos aqui relatados não significam que os alunos desenvolveram toda a potencialidade de pensamento possível em relação ao conceito de alienação, afinal, como afirma o próprio Vygotski:

Qualquer significado da palavra em qualquer idade constitui uma generalização. Mas os significados das palavras evoluem. No momento em que a criança assimila uma palavra nova, relacionada com um significado, o desenvolvimento do significado da palavra não finaliza, mas apenas começa (1993, p. 184).

Podemos considerar que o processo de significação apresentado por Vigotski, estende-se também à aprendizagem de conceitos por adolescentes e adultos.

\section{Conclusão}

Realizamos essa investigação mobilizados pela necessidade de compreender como organizar o ensino de Filosofia, a fim de que supere a dicotomia entre o ensino de conceitos e o ensino da capacidade de pensar. Observamos que o desenvolvimento do pensamento teórico permite a unidade entre essas duas dimensões formativas que normalmente são vistas de forma estanque na área de ensino.

Após trilhados os caminhos da investigação teórica e empírica, reconhecemos que não nos é possível lançarmos certezas sobre a aprendizagem de todos os estudantes que participaram do experimento de modo que isso possa referendar a viabilidade da metodologia de ensino utilizada.

Observamos que algumas ações docentes foram significativas para a promoção da aprendizagem dos alunos, dentre elas: 
1) criação de uma situação-problema como mobilizadora da aprendizagem, no caso específico, mediante o uso da narrativa;

2) promoção de momentos de reflexão inter e intrapessoal, mediadas pelo professor, com foco no conceito central da aula;

3) realização de leitura orientada de textos clássicos de Filosofia;

4) apresentação de novas situações a serem analisadas com base no conceito aprendido, permitindo o movimento do abstrato ao concreto.

Contudo, destacamos que essas ações só fazem sentido nas aulas de Filosofia se vinculadas ao desenvolvimento de um pensamento mediado pelos conceitos filosóficos. Pois, consideramos que o ponto de unidade entre o motivo do professor e o motivo dos alunos em uma atividade de ensino é o conteúdo escolar, e em nosso caso específico, os conceitos filosóficos que se fazem presentes nos textos clássicos da Filosofia. A aprendizagem dos conceitos filosóficos é o meio para instrumentalizar os alunos para realizar a crítica consistente da realidade.

Mesmo alcançando alguns resultados, os dados apresentados não têm a pretensão de oferecer um "modelo" de ensino, pois reconhecemos alguns limites na nossa própria condução das atividades. A sala de aula tem uma dinâmica rápida. Por mais que o professor suponha-se preparado, depara-se com imprevistos, já que a aula envolve relações humanas que, felizmente, não são totalmente controláveis. Quando se dá a voz ao aluno, criando uma relação de interação, os desdobramentos, às vezes, escapam do controle do professor. Nesse sentido, nem sempre o professor faz a melhor intervenção que poderia ter feito, ou seja, nem sempre suas perguntas, seus comentários, suas sínteses são as melhores, uma vez que elas não estão prontas a priori, mas ocorrem à medida que vão se fazendo necessárias no contexto das aulas.

Acreditamos que o experimento didático corroborou uma das ideias iniciais desta pesquisa: a de que se aprende a filosofar quando se aprende Filosofia, pois constatamos que sem conceitos filosóficos os alunos não vão muito além do senso comum. No trabalho com o conceito de um determinado clássico, não se está visando a adesão do estudante às ideias do filósofo, tampouco o acúmulo de informação sobre os sistemas filosóficos. O que realmente se espera é que os alunos tenham acesso a uma forma mais sistemática do pensar, ao rigor necessário à elaboração de um argumento, ao caráter mais abstrato do pensamento sobre os fenômenos 
particulares. Desse modo, reafirmamos que a aprendizagem do filosofar é o fim do ensino, mas esse fim é alcançado quando os alunos aprendem a Filosofia.

\section{Referências}

AQUINO, Orlando Fernández. L. V. Zankov: aproximações à sua vida e obra. In: LONGAREZI, Andréa Maturano; PUENTES, Roberto Valdés. (Org.). Ensino desenvolvimental: vida, pensamento e obra dos principais representantes russos. Uberlândia: EDUFU, 2013. p. 233-261.

BELIERI, Cleder Mariano; SFORNI, Marta Sueli de Faria. O ensino de filosofia na atual LDB e nas Orientações Curriculares do Ensino Médio: uma tensão entre conteúdo escolar e o desenvolvimento humano. Revista do NESEF Filosofia e Ensino, Curitiba, v. 1, n. 1, p. 23-36, out./nov./dez. 2012/jan. 2013.

DAVIDOV, Vasili V. Tipos de generalización en la enseñanza. Habana: Editorial Pueblo y Educación, 1982.

DAVIDOV, Vasili V. La enseñanza escolar y el desarrollo psíquico: investigación teórica y experimental. Moscu: Editorial Progreso, 1988.

FREITAS, Raquel Aparecida Marra da Madeira. Pesquisa em didática: o experimento didático formativo. In: ENCONTRO DE PESQUISA EM EDUCAÇÃO DA ANPED - Centro-Oeste: desafios da produção e divulgação do conhecimento, 10., 2010, Uberlândia. Anais... Uberlândia, 2010. v. I, p. 1-11.

GALLO, Silvio. Metodologia do ensino de filosofia: uma didática para o ensino médio. Campinas: Papirus, 2012.

GORSKI, D. P. Lenguage y conocimiento. In: PENSAMENTO e lenguaje. Montevideo: Ediciones Pueblos Unidos, 1959.

HEGEL, G.W. F. Propedêutica filosófica. Lisboa: Edições 70, 1989.

KANT, Immanuel. Manual dos cursos de lógica geral. 2. ed. Campinas: UNICAMP, 2003.

LEONTIEV, Alexis. Dessarollo de La psiquis. La consciência humana. In. SMIRNOV, A. A.; LEONTIEV, Alexis; RUBISHTEIN, Sergei; TIEVPLOV, B. M. Psicologia. México: Grijalbo, 1969. p. 74-92.

LEONTIEV, Alexis. O desenvolvimento do psiquismo. São Paulo: Centauro, 2004.

LIBÂNEO, J. C.; FREITAS, R. A. M. M. Vygotsky, Leontiev, Davydov: três aportes teóricos para a teoria histórico-cultural e suas contribuições para a Didática. In: Congresso Brasileiro de História da Educação, 4., 2006, Gôiania. Anais... Gôiania, 2006. p. 1-11. Disponível em:

<http://www.sbhe.org.br/novo/congressos/cbhe4/individuais-coautorais/eixo03/Jose\%20

Carlos\%20Libaneo\%20e\%20Raquel\%20A.\%20M.\%20da\%20M.\%20Freitas\%20-\%20Texto.pdf>. Acesso em: 20 dez. 2010.

LIMA, Márcio Antônio Cardoso. A prática de ensino de filosofia num contexto de reestruturação capitalista: construção de uma experiência problematizadora com o ensino. 2005. 223f. Tese (Doutorado em Educação) - Programa de Pós-Graduação em Educação, Universidade Federal de Minas Gerais, Belo Horizonte, 2005.

LURIA, Alexander Romanovich. Curso de psicologia geral: introdução evolucionista à psicologia. Rio de Janeiro: Civilização Brasileira, 1994. 
MOURA, Manoel Oriosvaldo de; MOURA, Anna Regina Lanner de. Escola um espaço cultural: matemática na educação infantil: conhecer, (re)criar - um modo de lidar com as dimensões do mundo. São Paulo: Diadema/SECEL, 1998.

RODRIGO, Lidia Maria. Uma alternativa para o ensino de filosofia no ensino médio. In. SILVEIRA, Renê José Trentin; GOTO, Roberto. Filosofia no ensino médio: temas, problemas e propostas. São Paulo: Loyola, 2007. p. 37-52.

RUBTSOV, Vitaly. A atividade de aprendizado e os problemas referentes à formação do pensamento teórico dos escolares. In: GARNIER, Catherine; BEDNARZ, Nadine; ULANOVSKAYA, Irina. (Org.). Após Vygotsky e Piaget: perspectivas social e construtivista escolas russa e ocidental. Porto Alegre: Artes Médicas, 1996. p. 129-137.

RUBINSTEIN, S. L. El pensamiento y los caminos de su investigación. Uruguay: Montevideo: Ediciones Pueblos Unidos, 1959.

SARTRE, Jean Paul. O existencialismo é um humanismo. In: MARÇAL, J. (Org.). Antologia de textos filosóficos. Curitiba: Secretaria de Estado da Educação do Paraná, 2009. v. 1, p. 616-639.

SEMENOVA, Marina. A formação teórica e científica do pensamento nos escolares. In: GARNIER, Catherine; BEDNARZ, Nadine; ULANOVSKAYA, Irina. (Org.). Após Vygotsky e Piaget: perspectivas social e construtivista escolas russa e ocidental. Porto Alegre: Artes Médicas, 1996. p. 160-168.

SFORNI, Marta Sueli de Faria. Aprendizagem conceitual e organização do ensino: contribuições da teoria da atividade. Araraquara: Junqueira \& Marin, 2004.

SFORNI, Marta Sueli de Faria. Interação entre Didática e Teoria Histórico-Cultural. Educação \& Realidade, Porto Alegre, v. 40, n. 2, p. 375-397, jun. 2015. Disponível em: <http://dx.doi.org/10.1590/2175-623645965>. Acesso em: 28 jul. 2016.

VALENTE, Célia. O salto para a vida. Curitiba: FTD, 1999.

VIGOTSKI, Lev Semenovitch. A construção do pensamento e da linguagem. São Paulo: Martins Fontes, 2000.

VYGOTSKI, Lev Semenovitch. Obras escogidas. Madrid: Visor, 1993. v. 2.

Cleder Mariano Belieri - Universidade Estadual de Maringá. Maringá | PR | Brasil. Contato: bellieri@gmail.com

Marta Sueli de Faria Sforni - Universidade Estadual de Maringá. Maringá | PR | Brasil. Contato: martasforni@uol.com.br 